\title{
REFINEMENTS AND REVERSES OF YOUNG TYPE INEQUALITIES
}

\author{
CHANGSEN YANG AND YU LI
}

Abstract. Recently, some Young type inequalities have been promoted. The purpose of this paper is to give further refinements and reverses to them. Meanwhile, on the base of the scalars results, we obtain some corresponding operator inequalities and matrix versions including HilbertSchmidt norm, unitarily invariant norm, trace norm, which can be regarded as an application of the scalar inequalities.

Mathematics subject classification (2010): 15A15, 15A42, 15A60, 47A30.

Keywords and phrases: Young type inequality, Hilbert-Schmidt norm, trace, unitarily invariant norm.

\section{REFERENCES}

[1] A. Burqan, M. KhANDAQJi, Reverse of Young type inequalities, Journal of Mathematical Inequalities 9,1(2015), 113-120.

[2] R. Bhatia, Matrix Analysis, Spring-Verlag, New York, 1997.

[3] S. FURUICHI, Alternative proofs of the generalized reverse Young inequalities, Adv. Inequal. Appl., 12(2017), 1-6.

[4] S. Furuichi, M. B. Ghaemi And N. Gharakhanlu, Generalized reverse Young and Heinz inequalities, Bull. Malays. Math. Sci. Soc., 42, 1(2019), 267-284.

[5] T. Furuta, J. MićIĆ Hot, J.PeČARIĆ, Mond-Pečarić Method in Operator Inequalities, Element, Zagreb, 2005.

[6] F. Hiai AND H. Kos AKI, Means for matrics and comparison of their norms, Indian Univ. Math. J., 48, 3(1999), 899-936.

[7] X. HU, Young type inequalities for matrices, Journal of East China Normal University (Natural Science), $\mathbf{4}(2012), 12-17$.

[8] F. Kittaneh, Y. ManasRah, Improved Young and Heinz inequalities for matrices, J. Math. Anal. Appl., 361(2010), 262-269.

[9] F. KitTaneh, Norm inequalities for fractional powers of positive operators, Lett. Math. phys., 27(1993), 279-285.

[10] H. Kos AKI, Positive definiteness of functions with applications to operator norm inequalities, Mem. Amer.Math.soc., 212(997), 2011.

[11] F. Kubo And T. Ando, Means of positive operators, Math. Ann., 264(1980), 205-224.

[12] L. NASiRi, M. Shakoori, W. LiaO, A note on the Young type inequalities, Int. J. Nonlinear Anal. Appl., 8, 1(2017), 261-267.

[13] M. Sababheh and D. Choi, A complete refinement of Young's inequality, J. Math. Anal. Appl., 440(2016), 379-393.

[14] X. ZHAN, Matrix Inequalities, Springer-Verlag, New York, 2002.

[15] J. ZHAO, J. Wu, Operator inequalities involving improved Young and its reverse inequalities, J. Math. Anal. Appl., 421, 2(2015), 1779-1789. 